\title{
Relationship Between Lower Extremity Strength Asymmetry And Jump And Sprint Performance
}

\author{
Celil KAÇOĞLU 1
}

\author{
${ }^{1}$ Eskişehir Technical University, Sport Sciences Faculty, Coaching Education, Eskişehir, Turkey \\ Address Correspondence to C. Kaçoğlu, e-mail: celilkacoglu@gmail.com
}

\begin{abstract}
The relationship between inter-limb strength asymmetry and athletic performance is not clearly well-known. Different results in the literature makes it difficult to form a common consensus on this issue. The aim of this study was to investigate the relationship between contralateral inter-limb strength asymmetry (ILLSA) values and jump and sprint performances. Fortyeight individuals $(21.5 \pm 2.8$ years, $1.74 \pm 0.1 \mathrm{~m}, 67.3 \pm 9.7 \mathrm{~kg}$ ) voluntarily participated in this study. All participants participated in squat (SJ), Countermovement jump (CMJ), 40m sprint run tests and right and left isokinetic concentric knee flexion and extension strength (IS) test at low $\left(60^{\circ} . \mathrm{s}-1\right)$ and high $\left(300^{\circ} . \mathrm{s}-1\right)$ angular velocities. The symmetry angle formula was used in order to determine the isokinetic knee strength asymmetry values between inter-lower limb. According to the results it was revealed that there was no relation $(p>0.05)$ between ILSSA at low and high angular velocities and squat jump $(r=-0.106-0.200)$, countermovement jump $(\mathrm{r}=-0.11-0.087)$ and $40 \mathrm{~m}$ sprint $(\mathrm{r}=0.012-0.810)$ performance. In conclusion, there is no negative or positive relationship between inter limb isokinetic knee strength symmetry angle and jump and sprint performances in physically active individuals.
\end{abstract}

Key words: Imbalance Sprint Performance, Isokinetic Strength, Muscle Balance, Vertical Jump

\section{INTRODUCTION}

While in most of the sports branches (long jump, high jump, 100m, 200m sprint), reaching maximum jump height and sprint speeds determines the winner, however it does not affect the result in some sports (volleyball, basketball, football etc.) jump and sprint are performance components that are performed repeatedly in many sports branches and are very important to win. It is stated that there is a direct relationship between jump and sprint performances and muscular strength such as lower extremity strength, strengthvelocity relationship or indirect relationship such as strength generation rate and also that individuals with more muscle strength are better at jump and sprint performances than those with less muscle strength (36).

In humans, there is a tendency to use one side of the body in motor activities such as jump and sprint. This preference tendency is due to the fact that one hemisphere is dominant over the other, which is called cerebral dominance. This preference in humans is usually seen as a preference for the hand or foot on a particular side during a motor skill. This is usually associated with mechanical asymmetry, which is defined as a kinetic / kinematic difference between the right and left sides of the lower extremity $(1,11,18)$. There are many studies showing that protecting the strength rate between both the agonist-antagonist muscles (HamstringQuadriceps) and the contralateral muscles in lower extremities (predominant and non-dominant or the right/left side of Hamstring-Hamstring or Quadriceps-Quadriceps) is very important in terms of both protection from injuries and elimination of losses which could develop during athletic performance $(10,14,21,28,38)$. Bilateral strength asymmetry, in the assessments of neuromuscular function of lower extremity, generally refers to the maximal strength difference between the two legs according to a reference point or the strength rate in relation to the contralateral muscle $(7,20,41)$.

In many research samples, the asymmetry index is obtained by calculating the percentage by taking the dominant or stronger side as a reference point (31). In the literature, there are different formulas such as right/left side ratio, asymmetry index, symmetry angle, which are symmetry- or asymmetry-oriented $(7,20,31,41)$. For example, the 
expression of that the left knee flexor strength is $15 \%$ lower than the right knee provides an opportunity of the assessment of asymmetry percentage in a simple way for coaches or sports experts. Along with that, the terms symmetry and asymmetry can be used in the same sense; while symmetry is defined as the ability of an extremity to reflect the movement of the other extremity in the same way, asymmetry means deviation from symmetry (16).

Strength is a basic performance component in many sports branches. The strength of the lower extremity muscle groups is very important to generate or absorb high strengths during athletic performances such as bounce, tapping, sprint, acceleration or deceleration. The isokinetic strength is defined as the maximum torque (turning moment) value that can be improved at all the angles of the movement during voluntary contraction at a stable angular velocity. Isokinetic dynamometers are electromechanical devices that can measure the performance of isokinetic muscle movements involving major joints. Isokinetic dynamometers are widely used in the tests determining of the strength difference between the lower extremities $(22,28,29$, 32).

While the effects of the inter-limb strength asymmetry index or symmetry angle on sports performance are not known clearly, there are different results in the literature. While there are results indicating that high asymmetry in strength is associated with the risk of disability (26), may limit athletic performance of the athlete (40) or may have a negative effect on jump performance (2), there are also study results indicating that high strength asymmetry is associated with a better performance (6). These different research results cause confusion for researchers and coaches. It can help coaches and sports experts plan strength training programs to reduce possible strength imbalances between the extremities that may be present in athletes and thus it can increase functional performance by reducing performance losses. Therefore, the aim of this study is to investigate whether there is a relationship between ILSSA and 40-meter sprint performances in physically active but not highly trained individuals.

\section{METHOD}

In this study, whether there is a relationship between isokinetic knee strength asymmetry angle and squat jump, countermovement jump and 40meter sprint time was investigated. The isokinetic knee strength was obtained by the peak torque obtained as a result of 5 maximal repetition of concentric flexion and extension at slow and fast (60 and $300^{\circ} . \mathrm{s}-1$ ) angular velocities. As for the jump, it was obtained by a jump test conducted with hands on hips and a mat that calculates the time spent in the air. The sprint time was measured with a photocell stopwatch.

\section{Participants}

The participants of this study were 50 volunteers who were physically active but not highly trained 35 male and 15 female and whose ages were 21.5 \pm 2.8 (average \pm standard deviation), heights were $1.74 \pm 0.1 \mathrm{~m}$, body weights were $67.3 \pm 9.7 \mathrm{~kg}$, body fat percentages were $14.4 \pm 5.6 \%$, and body mass indexes were $21.7 \pm 2.4 \mathrm{~kg} / \mathrm{m} 2$. In this cross-sectional study, all participants participated in all measurements. The criterion for inclusion in the study was determined as doing regular physical conditioning training for at least 2 days a week, and the criteria for exclusion were determined as having suffered from lower extremity sports injury or disability. All participants were verbally informed prior to the study, their informed consent was obtained with signatures after stating that they were going to participate in the study on a voluntary basis and be free to leave the study in any part of it. The study was performed in compliance with the Helsinki Declaration and approved by Eskişehir Osmangazi University Non-invasive Clinical Researches Ethical Committee (Date: 02/01/2019, No:25403353-050.99-E.291, Decision: 2018-308, Confirmation link: https://ebysnetm.ogu.edu.tr/Home/Dogrulama/6235 d729-673e-495e-b290-43168ffb7e27).

\section{Research Design}

One week before the measurements, all participants were given an introduction and trial of the measurements for their adaptation. On this trial day, the heights of the participants were measured with a fixed wall stadiometer (Holtain Ltd. UK), and the body weights and body fat percentages were measured with a bioelectrical impedance analyzer (Tanita MC 180MA, Japan). Measurements were taken on 2 different days and there were at least 48 hours between the measurements. On the first day of the measurements, jump and sprint tests were conducted and on the second day, isokinetic knee strength measurements were taken. It was stated verbally to the participants that they should not 
participate in heavy physical activities, take diuretics like caffeine or alcohol, that they should continue their routine diet and hydration and sleep for a sufficient time during the day before the measurements. The measurement days started with calisthenics involving dynamic stretches and submaximal dynamic contractions for approximately 10 minutes and warm-ups involving plyometric jumps. After warm-up, 3-5 minutes break was given for a passive rest and then the measurements started. Before every measurement, the content of the test was repeated verbally to the participants.

\section{Measurements and Analyses}

Squat Jump: SJ was measured as a vertical maximal jump (without moving up and down and not involving an eccentric phase and elastic energy) from a 1-2 seconds long half squat position in which the body is slightly forward in flexion, knees and hips are at approximately 950 flexion, eyes are looking across, hands are on waist, feet are shoulder width apart $(8,30)$.

Countermovement Jump: CMJ starts with a downward movement (eccentric phase) with knee and hip flexion from the standing position where the hands are on waist and the feet are shoulder width apart. It is an upward vertical jump with a knee and hip extension in a fluid and maximal way (stretchshortening cycle) without any pause after getting into the half-squat position $(8,23)$.

$\mathrm{SJ}$ and CMJ tests measured (with $1 \mathrm{~cm}$ precision) with a mat (Smartspeed, Fusion Sport, Australia) determining the time spent in the air during the jump with double leg (bilateral). The best of 3 attempts, which had one minute breaks between them, was recorded for analysis (30).

40-Meter Sprint Test: Sprint performances of the participants were determined by a flat running test at a maximum speed of 40 meters. The sprint test was performed on a closed athletic tartan track, which had a sufficient distance from the finish line for deceleration. Two pairs of photocells are positioned at the start (0. meter) and finish lines (40 meters). It was applied from the standing position between the starting line and the line which was approximately 1 meter behind this line with a high start and without pre-acceleration. Before the sprint test, at least two test runs at the submaximal speeds were performed by the participants and following this, the test was performed after a sufficient break was given. Sprint tests were measured twice with 0.01 seconds precision and the better performance was recorded for analysis. At least 2 minutes of active rest was given between two tests $(30,37)$.

Isokinetic Strength Test: Isokinetic knee strength tests were conducted by using an isokinetic dynamometer (Humac Norm Testing \& Rehabilitation System, Model TM 770, USA). On the measurement day, firstly the calibration of the device was done. After 10 minutes of general warmup including no-load cycling, the seat and dynamometer angle adjustment of the device was made according to the physical characteristics of the individual to be tested. Then the participant was fixed to the seat with calf and body belts which were tightened as so not to cause any disturbance. The test procedure was explained to the participants again and the participants were verbally motivated during the tests. The soft pad on the adjustable arm of the dynamometer is fixed to the leg from the proximal alignment of the medial malleol as so to allow the dorsal flexion of the participant's ankle. The axial rotation of the dynamometer arm is adjusted to the lateral femoral epicondyle alignment. Before each angular velocity, for warm-up and acclimatization 3 submaximal repetitions were performed and they were followed by a $30 \mathrm{sec}$ rest period. Then, it was completed with concentric 5 maximal flexion/extension movements at low $\left(60^{\circ} . \mathrm{s}-\right.$ 1) and high $\left(300^{\circ} . s-1\right)$ angular velocities with 1minute rest intervals between the angular velocities. The tests were performed on right and left extremities and at the end of the test, peak torque values $(\mathrm{Nm})$ were recorded via a computer connected to the device $(9,12,15)$.

Asymmetry Analysis: While very different asymmetry indexes $(4,20,31,34)$ are used in calculation of asymmetry between extremities, the results of these calculations may differ from each other. In the simplest form, an asymmetry calculation can be calculated as a percentage by taking the predominant or stronger side as a reference value (Equilibrium 1 ). The symmetry angle formula can reveal the direction of the asymmetry by using the values of the right and left sides as a vector. If the result is negative in the symmetry angle, it shows that the left side value is higher; if positive, it shows that right side value is higher (41). In addition to this, in this study, contralateral isokinetic knee strength asymmetry values of each 
participant were determined with the symmetry angle of Zifchock et al. (41) (Equilibrium 2), because it uses a standard reference point in interpreting lateral dominance and decreases the possibility of artificial inflation of the data. In this formula, if the symmetry angle value is $0 \%$, it means that it is perfectly symmetrical (7).

Asym $\%=\frac{\max -\min }{\max } * 100$

(1)

$\theta_{\text {sy }}=\frac{\left(45^{\circ}-\arctan \left(\frac{\text { Xleft }}{\text { Xright }}\right)\right)}{90^{\circ}} * 100 \%$

$\theta \_$sym:symmetry angle, Xleft:left side isokinetic strength value, Xright:right side isokinetic strength value

\section{Statistical Analysis}

The sample size was calculated by using a statistical power analysis software (Gpower 3.1.9.2, Brunsbuttel, Germany). Assuming the effect size $=$ 0.3 (medium), $\mathrm{P}=0.05$, power $(1-\beta)=0.7$, the minimum sample size, according to the apriori power analysis result, was 47 participants (30). Descriptive statistics were given as average, standard deviation. The Shapiro-Wilk test $(\mathrm{p}>0.05)$ showed that all the data were normally distributed and it was observed that there was no extreme value. Pearson Correlation Coefficient Analysis was used to determine the relationship between isokinetic knee flexion and extension strength asymmetry values at slow and fast angular velocities and the average values of SJ, CMJ and $40 \mathrm{~m}$ sprint performance. The alpha value for the statistical significance was set at 0.05. All statistical analyses were calculated by using SPSS v20 computer software (IBM SPSS Inc., IL, USA). In order to determine the correlation level, $\mathrm{r}=0-0.3$ was set to be weak, $r=0.3-0.6$ to be medium, $r=0.6-0.9$ to be strong, $0.9-1$ to be very strong and 1 was set to be full correlation (19).

\section{RESULTS}

The performance values of 40 meters sprint, squat and countermovement jump and the values (Table 1) and flexion-extension knee isokinetic strength and inter-limb contralateral strength symmetry angle are shown in Table 2.

Table 1. SJ, CMJ, 40m sprint average and standard deviation values

\begin{tabular}{lcc}
\hline Performance Parameters & Mean & Standard Deviation \\
\hline Countermovement jump height $(\mathrm{cm})$ & 35.3 & 7.1 \\
\hline Squat jump height $(\mathrm{cm})$ & 31.8 & 6.1 \\
\hline $40 \mathrm{~m}$ sprint time $(\mathrm{s})$ & 5.80 & 0.57 \\
\hline
\end{tabular}

Table 2. Isokinetic knee strength, symmetry angle and asymmetry index values

\begin{tabular}{|c|c|c|c|c|c|c|c|}
\hline \multirow{2}{*}{\multicolumn{2}{|c|}{ Isokinetic Parameters }} & \multicolumn{3}{|c|}{$60^{\circ} . \mathrm{s}^{-1}$ Angular Velocity } & \multicolumn{3}{|c|}{$300^{\circ} . \mathrm{s}^{-1}$ Angular Velocity } \\
\hline & & $\begin{array}{l}\text { Torque value } \\
\qquad(\mathrm{Nm})\end{array}$ & $\begin{array}{c}\text { Symmetry angle } \\
\left(\theta_{\text {sym }}\right)\end{array}$ & $\begin{array}{c}\text { Asymmetry } \\
\text { index }(\%)\end{array}$ & $\begin{array}{c}\text { Torque value } \\
\qquad(\mathrm{Nm})\end{array}$ & $\begin{array}{c}\text { Symmetry angle } \\
\left(\theta_{\text {sym }}\right)\end{array}$ & $\begin{array}{c}\text { Asymmetry } \\
\text { index }(\%)\end{array}$ \\
\hline \multirow{2}{*}{ Flexion } & Right & $131.5 \pm 34.1$ & \multirow{2}{*}{$1.26 \pm 3.44$} & \multirow{2}{*}{$8.7 \pm 5.9$} & $85.6 \pm 20.9$ & \multirow{2}{*}{$0.26 \pm 3.13$} & \multirow{2}{*}{$7.3 \pm 5.4$} \\
\hline & Left & $126.1 \pm 31.5$ & & & $84.7 \pm 19.5$ & & \\
\hline \multirow{2}{*}{ Extension } & Right & $178.7 \pm 47.5$ & \multirow{2}{*}{$0.56 \pm 3.32$} & \multirow{2}{*}{$7.3 \pm 6.4$} & $94.0 \pm 25.1$ & \multirow{2}{*}{$1.11 \pm 2.72$} & \multirow{2}{*}{$7.5 \pm 4.5$} \\
\hline & Left & $175.3 \pm 45.6$ & & & $90.8 \pm 24.8$ & & \\
\hline
\end{tabular}

ort \pm ss, Nm: Newtonmeter, $\theta_{\text {sym }}$ : Symmetry angle (Zifchock et al., 2008), \%: Asymmetry angle (Impellizzeri et al., 2007)

Table 3, shows the relationship between the inter-limb strength symmetry angle values and jump and sprint performances. There was no statistically significant relationship ( $\mathrm{p}>0.05)$ between the contralateral strength symmetry angle values and squat jump, countermovement jump and 40 meters sprint performances (Table 3).

Table 3. The relationship between contralateral inter-limb strength symmetry angles and SJ, CMJ and 40m sprint performance (Pearson's correlation test).

\begin{tabular}{|c|c|c|c|c|c|c|c|}
\hline \multirow[t]{2}{*}{ Symmetry Angles Values } & & \multicolumn{2}{|c|}{ SJ } & \multicolumn{2}{|c|}{$\mathrm{CMJ}$} & \multicolumn{2}{|c|}{ 40m sprint } \\
\hline & & $r$ & $p$ & $R$ & $p$ & $r$ & $p$ \\
\hline Extension symmetry & $60^{\circ} . \mathrm{s}^{-1}$ & -0.106 & 0.473 & -0.116 & 0.434 & 0.016 & 0.916 \\
\hline Flexion symmetry & $60^{\circ} \cdot \mathrm{s}^{-1}$ & 0.024 & 0.870 & 0.010 & 0.948 & 0.012 & 0.938 \\
\hline Extension symmetry & $300^{\circ} \cdot \mathrm{s}^{-1}$ & 0.200 & 0.892 & 0.087 & 0.557 & 0.810 & 0.583 \\
\hline Flexion symmetry & $300^{\circ} \cdot \mathrm{s}^{-1}$ & 0.050 & 0.737 & 0.062 & 0.678 & 0.090 & 0.542 \\
\hline
\end{tabular}

SJ: Squat jump, CMJ: Countermovement jump 


\section{DISCUSSION}

The aim of this study was to investigate the relationship between inter-limb flexion and extension isokinetic knee strength asymmetry at low and high angular velocities and sprint and jump in physically active and healthy individuals. The main findings of this study are that there is no significant relationship between inter-limb strength asymmetry and SJ, CMJ and 40m sprint performances. There are different research results in the literature about the relationship between asymmetry and jump and sprint performance. While there are studies indicating that there is a negative correlation between Quadriceps and Hamstring strength asymmetry and SJ and CMJ performances (13), there are also studies indicating that contralateral knee extensor asymmetry has no effect on jumping in volleyball players (35).

The SJ and CMJ findings of this study show parallelism with Yoshioka et al.'s (39) and Bell et al.'s (5) results revealing that $10 \%$ bilateral strength asymmetry does not affect jump performance. In addition, it also have parallels with Maloney et al.'s (25) study whose results have indicated that there is no correlation between the asymmetry determined particularly by the movement of depth jump measured unilaterally and jump height and reactive strength index. According to these results, although the strength outputs between the right and left extremities do not differ, it can be said that there is no difference in jump performance in relation to the symmetrical extremities and the stronger extremity can compensate the strength loss of the weak side. According to the results of this study, the fact that the strength asymmetry in the range of $7.3-8.7 \%$ (Table 1), based on the index calculation of Impellizzeri et al. (20), does not affect the SJ and CMJ performance negatively or positively might have derived from this.

There are also studies indicating that there is a negative correlation between strength asymmetry and jump performance (2). According to the results of this study, it can be said that there is no positive or negative correlation between right and left quadriceps and hamstring isokinetic strength asymmetry at low and high angular velocities and bilateral closed kinetic chain activities involving stretch and shortening cycle like jump and performances involving cyclic activity like sprint. In addition, it can also be said that although inter-limb strength differences were observed, functional athletic performance was not positively or negatively affected by this. The result of the studies of Bailey et al. (2) and Bazyler et al. (3), stating that asymmetry has a negative effect on unloaded jumps and jumps loaded with $20 \mathrm{~kg}$, might derive from the fact that the heights and weights of the participants of these studies were relatively above the average. Accordingly, it can be considered that the physical and anthropometric properties of athletes may further enhance the effects of asymmetry on athletic performance. Future studies might be aimed to investigate the degree of impact of physical properties on the effect of asymmetry on performance.

According to the results of this study, it was observed that there was no statistical relationship between concentric flexion and extension knee strength asymmetry at high and low angular velocities and 40m sprint time. Lockie et al. (24) stated that in individuals playing team sports with strength training, there was a negative correlation between concentric isokinetic knee strength asymmetry at 180 and $240^{\circ} . \mathrm{s}^{-1}$ angular velocities and $40 \mathrm{~m}$ sprint time. Sannicandro et al. (33) stated that in elite football players, ILSSA, measured functionally, affected $10 \mathrm{~m}$ sprint time but did not have effect on $20 \mathrm{~m}$ sprint time. In addition, Coratella et al. (13) reported that in elite young football players, there was a positive correlation between inter-limb hamstring isokinetic strength asymmetry at high angular velocities $\left(300^{\circ} . \mathrm{s}^{-1}\right)$ and 10 and $30 \mathrm{~m}$ sprint. Meyers et al. (27) stated that there was no relationship between asymmetry and maximal sprint in 11-16 years old males. Considering the results of this study, there are very different results in the literature about the relationship between asymmetry and sprint.

According to the obtained results, it is observed that in healthy individuals, approximately $7-8 \%$ inter-lower extremities strength difference has no negative effect on jump and sprint performance. However, the diversity in the results of the studies is insufficient to create a consensus about the effects of asymmetry. For this reason, if the coaches and sports experts, aiming to decrease asymmetry, carry out asymmetry evaluations specific to sports branch, training level and physical characteristics of the individuals and movement in their studies related to 
asymmetry, they will get more accurate results. The fact that this study's being limited to concentric isokinetic strength asymmetry might have an effect on the results should be taken into account. In addition, in future studies, contralateral and ipsilateral extremity asymmetry can be evaluated as well as that how asymmetry is affected by individual anthropometric or physical properties can be researched. In addition to the lower body asymmetry, there is a need for more studies on

\section{CONCLUSIONS}

People have a tendency to use one side of the body during physical activities (18). This is seen in the form of a hand or foot on a particular side during a physical activity (11). It is accepted that this preference tendency is caused by the dominance of a hemisphere called cerebral dominance over the other hemisphere (1). This means that a hemisphere is more responsible than the other in a particular function. This is usually associated with mechanical asymmetry, which is defined as a kinetic/kinematic difference between the left and right sides of the lower extremity (18). It can be thought that dominance in some athletic performances may affect asymmetry with the laterality, task- and/or sportspecific effects and cerebral dominance. According to the results of this study, it can be seen that athletic performances such as jumping and sprinting didn't affected by the strength asymmetry. In the light of these results, it is thought that it will give an idea to coaches and sports experts in determining the specific nature of the sport or the specific training programs specific to the sport. Besides that, the results suggest that the lower limbs may be able to tolerate jumping and sprinting performances in return to sport after injuries.

As a conclusion, according to the results of this study, there is no negative or positive relationship between inter-lower limb concentric isokinetic knee strength symmetry angle at high and low angular velocities and jump and sprint performances in physically active but not highly trained healthy individuals.

\section{REFERENCES}

1. Aliosmanoğlu B, Köçkar Ç. Üniversite Öğrencilerinde El Tercihinin ve Dominant Gözün Bazı Hastalıklar ile İlişkisi (The Relationship of Hand Dominance and Dominant Eye to Some Diseases of University Students). Eur J Basic Med Sci, 2014;4(3), 53-57. asymmetry between upper extremities. The investigation of possible adaptive changes in strength asymmetry, balance asymmetry or other different asymmetry evaluations as a result of different training methods will provide useful information for a more accurate understanding of the effects of asymmetry on athletic performance.

2. Bailey $\mathrm{C}$, Sato $\mathrm{K}$, Alexander $\mathrm{R}$, Chiang $\mathrm{CY}$, Stone $\mathrm{MH}$. Isometric force production symmetry and jumping performance in collegiate athletes. J. Trainol. 2013;2(1):1-5.

3. Bazyler CD, Bailey CA, Chiang CY, Sato K, Stone MH. The effects of strength training on isometric force production symmetry in recreationally trained males. J Trainol. 2014; 3(1), 6-10.

4. Becker HP, Rosenbaum D, Kriese T, Gerngroß H, Claes L. Gait asymmetry following successful surgical treatment of

5. ankle fractures in young adults. Clin Orthop Relat Res. 1995; 311, 262-269.

6. Bell DR, Sanfilippo JL, Binkley N, Heiderscheit BC. Lean mass asymmetry influences force and power asymmetry during jumping in collegiate athletes. J Strength Cond Res. 2014; 28(4), 884 .

7. Bini RR, Hume PA. Relationship between pedal force asymmetry and performance in cycling time trial. J Sports Med Phys Fitness. 2015; 55(9), 892-898.

8. Bishop C, Read P, Chavda S, Turner A. Asymmetries of the lower limb: The calculation conundrum in strength training and conditioning. Strength Cond J. 2016; 38(6), 27-32.

9. Bosco C, Komi PV. Potentiation of the mechanical behavior of the human skeletal muscle through prestretching. Acta Physiol Scand. 1979; 106(4), 467-472.

10. Brown LE, Whiteburst M. Load range. In: Isokinetics in Human Performance. Brown, LE, ed. Human Kinetics. 2000: 114.

11. Burkett LN. Causative factors in hamstring strains. Med Sci Sports Exerc. 1970; 2(1), 39-42.

12. Carpes FP, Mota CB, Faria IE. On the bilateral asymmetry during running and cycling-A review considering leg preference. Phys Ther Sport. 2010; 11(4), 136-142.

13. Chan KM, Maffulli N, Korkia RCT, eds. Principles and Practice of Isokinetics in Sports Medicine. Hong Kong: Williams \& Wilkins; 1996: 117-122.

14. Coratella G, Beato M, Schena F. Correlation between quadriceps and hamstrings inter-limb strength asymmetry with change of direction and sprint in U21 elite soccerplayers. Hum Mov Sci. 2018; 59, 81-87.

15. Croisier JL, Forthomme B, Namurois $\mathrm{MH}$, Vanderthommen M, Crielaard JM. Hamstring muscle strain recurrence and strength performance disorders. Am J Sports Med. 2002; 30(2), 199-203.

16. Davies GJ, Heiderscheit B, Brinks K. Test interpretation. In: Isokinetics in Human Performance. Brown, LE, ed. IL, USA: Human Kinetics, 2000: 13, 114.

17. Exell T, Irwin G, Gittoes M, Kerwin D. Implications of intralimb variability on asymmetry analyses. J Sports Sci. 2012; 30(4), 403-409.

18. Faul F, Erdfelder E, Lang AG, Buchner A. G*Power 3: A flexible statistical power analysis program for the social, 
behavioral, and biomedical sciences. Behav Res Methods. 2007; 39, 175-191.

19. Girard O, Brocherie F, Morin JB, Millet GP. Lower limb mechanical asymmetry during repeated treadmill sprints. Hum Mov Sci. 2017; 52, 203-214.

20. Hopkins WG. Measures of reliability in sports medicine and science. Sports Med. 2000; 30, 1-15.

21. Impellizzeri FM, Rampinini E, Maffiuletti N, Marcora SM. A vertical jump force test for assessing bilateral strength asymmetry in athletes. Med Sci Sports Exer. 2007; 39(11), 2044-2050.

22. Keeley DW, Plummer HA, Oliver GD. Predicting asymmetrical lower extremity strength deficits in collegeaged men and women using common horizontal and vertical power field tests: A possible screening mechanism. J Strength Cond Res. 2011; 25(6), 1632-1637.

23. Kobayashi Y, Kubo J, Matsubayashi T, Matsuo A, Kobayashi $\mathrm{K}$, Ishii N. Relationship between bilateral differences in single-leg jumps and asymmetry in isokinetic knee strength. J Appl Biomechs. 2013; 29(1), 61-67.

24. Linthorne NP. Analysis of standing vertical jumps using a force platform. Am J Phys. 2001; 69(11), 1198-1204.

25. Lockie RG, Shultz AB, Jeffriess MD, Callaghan SJ. The relationship between bilateral differences of knee flexor and extensor isokinetic strength and multi-directional speed. Isokinet Exerc Sci. 2012; 20(3), 211-219.

26. Maloney SJ, Richards J, Nixon DGD, Harvey LJ, Fletcher IM. Vertical stiffness asymmetries during drop jumping are related to ankle stiffness asymmetries. Scand J Med Sci Sports. 2017; 27, 661-669.

27. McCall A, Carling C, Nedelec M, Davison M, Le Gall F, Berthoin S, Dupont G. Risk factors, testing and preventative strategies for non-contact injuries in professional football: Current perceptions and practices of 44 teams from various premier leagues. Br J Sports Med. bjsports-2014.

28. Meyers RW, Oliver JL, Hughes MG, Lloyd RS, Cronin JB. Asymmetry during maximal sprint performance in 11- to 16year-old boys. Pediatr Exerc Sci. 2017; 29(1), 94-102.

29. Newton RU, Gerber A, Nimphius S, Shim JK, Doan BK, Robertson M, Kraemer WJ. Determination of functional strength imbalance of the lower extremities. J Strength Cond Res. 2006; 20(4), 971-977.

30. Nitschke JE. Reliability of isokinetic torque measurements: A review of the literature. Aust J Physiother. 1992; 38(2), 125134.

31. Potach DH, Chu DA. Program Design and Technique for Plyometric Training. In: Essentials of strength training and conditioning. 4th edition. Haff GG, Triplett NT, eds. IL, USA: Human kinetics; 2015: 238, 474.

32. Robinson RO, Herzog W, Nigg BM. Use of force platform variables to quantify the effects of chiropractic manipulation on gait symmetry. J Manipulative PhysiolTher. 1987; 10(4), 172-176.

33. Şahin Ö. Isokinetic Measurements in Rehabilitation. Cumhuriyet Med J. 2010; 32(4), 386-396.

34. Sannicandro I, Piccinno A, Rosa RA, De Pascalis S. Correlation between functional asymmetry of professional soccer players and sprint. Br J Sports Med. 2011; 45, 370-371.

35. Sato K, Heise GD. Influence of weight distribution asymmetry on the biomechanics of a barbell back squat. J Strength Cond Res. 2012; 26(2), 342-349.

36. Schons P, Da Rosa RG, Fischer G, Berriel GP, Fritsch CG, Nakamura FY, et al. The relationship between strength asymmetries and jumping performance in professional volleyball players. Sports Biomech. 2018; 36, 1-12.

Turk ل Sport Exe 2019; 21(2): 204-210

๑ 2019 Faculty of Sport Sciences, Selcuk University
37. Suchomel TJ, Nimphius S, Stone MH. The importance of muscular strength in athletic performance. Sports Med. 2016; 46(10), 1419-1449.

38. Woolford SM, Polglaze T, Rowsell G, Spencer M. Field testing principles and protocols. In: Physiological Tests for Elite Athletes. 2nd ed. Australian Institute of Sport. Tanner R, Gore C, eds. IL, USA: Human Kinetics; 2013: 237.

39. Wyatt MP, Edwards AM. Comparison of quadriceps and hamstring torque values during isokinetic exercise. J Orthop Sports PhysTher. 1981; 3(2), 48-56.

40. Yoshioka S, Nagano A, Hay DC, Fukashiro S. The effect of bilateral asymmetry of muscle strength on the height of a squat jump: A computer simulation study. J Sports Sci. 2011; 29(8), 867-877.

41. Young WB, James R, Montgomery I. Is muscle power related to running speed with changes of direction? J Sports Med Phys Fitness. 2002; 42(3), 282-288.

42. Zifchock RA, Davis I, Higginson J, Royer T. The symmetry angle: A novel, robust method for quantifying asymmetry. Gait Posture. 2008; 27(4), 622-627. 